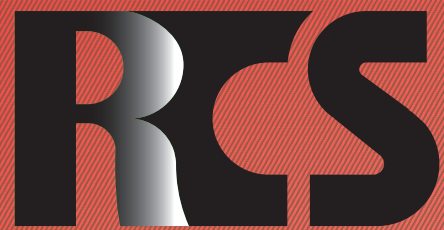

Depósito legal ppi $201502 Z U 4662$

Esta publicación científica en formato digital es continuidad de la revista impresa Depósito Legal: pp $197402 Z$ Z789

- ISSN: 1315-9518 • ISSN-E: 2477-9431

Universidad del Zulia. Revista de la Facultad de Ciencias Económicas y Sociales Vol. XXVI. No. 1

Enero-Marzo, 2021 


\title{
Medidas contra el despoblamiento: Proyecto Marca Pueblo
}

\author{
Milán García, Juan*
}

\begin{abstract}
En los últimos años se está produciendo
\end{abstract} un fenómeno demográfico caracterizado por una disminución de la población de los municipios rurales en favor de los principales centros de actividad económica, las ciudades. Este proceso desemboca, a su vez, en la pérdida progresiva de las actividades socioeconómicas que se realizan en los territorios rurales, reduciéndose a la celebración anual de festividades locales, actividad de pequeñas empresas en la localidad y la provisión de servicios públicos básicos como educación o sanidad, los cuales están en riesgo de deterioro y desaparición ante la falta de personas que demanden dichos servicios.

Este éxodo rural se ha visto acelerado en los últimos años por el desarrollo de las nuevas Tecnologías de la Información y la Comunicación (TIC). La revolución digital no ha permeado de la misma manera en las ciudades que en los territorios rurales: Mientras que en las primeras es prácticamente imposible conocer a algún familiar, amigo o compañero de trabajo que no disponga de ordenador, teléfono móvil o tenga conexión a internet de alta velocidad en su domicilio; en los municipios rurales, la gran parte de la población cuenta, como mucho, con red de telefonía básica en casa y televisor.

La disponibilidad y acceso a estas infraestructuras tecnológicas tiene un impacto positivo en los principales componentes de la demanda agregada: Consumo privado e inversión empresarial. Por un lado, las TIC facilitan en gran medida el proceso productivo de las empresas, fomentando la instalación de nuevas organizaciones en ciudades. Por otro lado, estas herramientas facilitan la compra de bienes y servicios sin necesidad de trasladarse a la tienda física, incrementando el nivel de consumo de la economía. En conjunto, este avance tecnológico ha contribuido a incrementar la brecha socioeconómica entre el entorno urbano y el rural.

Ante esta situación, han surgido diversos movimientos para revertir el proceso de éxodo rural y evitar que los pequeños municipios rurales que aún quedan, sobrevivan en el largo plazo. Entre estos proyectos se encuentra el denominado "Marca Pueblo", registrado ya en la Oficina Española de Patentes y Marcas. Englobado en el Grupo Almeriense de Economía Aplicada (SEJ-147) de la Universidad de Almería (España), el objetivo

* Profesor Investigador del Área de Economía Aplicada del Departamento de Economía y Empresa de la Universidad de Almería, España. E-mail: jmg483@ual.es iD ORCID: https://orcid.org/0000-00032718-0024 
de este proyecto de investigación consiste en revitalizar la economía local de los municipios rurales de la provincia de Almería a través del empleo de los recursos endógenos de los que disponen, con el fin de que dicha revitalización sea sostenible a lo largo del tiempo.

En esta primera fase del proyecto están participando seis municipios de la provincia de Almería: Alcóntar, Almócita, Líjar, Lubrín, Purchena y Serón. Se trata de municipios pequeños con una población de menos de 2.000 habitantes y una pirámide poblacional muy envejecida, en los que la actividad económica principal se centra especialmente en el sector agrícola, ganadero y de la manipulación de mármol. La elevada concentración de la actividad económica local en un sector específico, junto a la insuficiencia de servicios públicos básicos y posibilidades de ocio, ha provocado que la población joven se desplace a los grandes núcleos de población urbano, lo que reduce el grado de sostenibilidad del municipio rural.

Actualmente el proyecto se encuentra en una primera etapa de diagnóstico. A partir de la aplicación de una serie de metodologías de desarrollo local sostenible se están definiendo las características socioeconómicas de cada municipio y se están identificando con qué recursos endógenos cuenta cada uno para aportar valor añadido $\mathrm{y}$ diferenciador a su actividad económica potencial. Las metodologías utilizadas comprenden, entre otras, herramientas de lluvia de ideas, como la tabla de aspectos Positivos, Interesantes y Negativos (PIN); de análisis del entorno interno y externo del municipio, como la matriz de Debilidades, Amenazas, Fortalezas y Oportunidades (DAFO) o Globo Volador y de análisis estratégico, como la matriz de Marco Lógico.

Los datos que se analizan provienen de la realización de entrevistas a los principales agentes locales comprometidos con la labor de dinamizar la actividad socioeconómica del municipio: Desde habitantes del municipio, empresarios de la zona, representantes de asociaciones, hasta miembros del equipo de gobierno local. De esta manera se consigue aplicar un enfoque bottom-up en el que los ciudadanos de los municipios se sienten partícipes de todo el proyecto y les motive a actuar activamente en favor de la sostenibilidad socioeconómica del territorio. Las expectativas de obtener resultados positivos son tan elevadas que se está preparando una ampliación de municipios que participan en el proyecto.

Las perspectivas de futuro de los municipios rurales no son nada alentadoras. $\mathrm{Si}$ este proceso de despoblamiento sigue avanzando sin control, el abandono de gran parte de territorios rurales provocará la extinción de la diversidad cultural de los países en favor de unos núcleos de población urbanos con unos niveles de densidad demográficas insostenibles. Los centros de enseñanza e investigación como las universidades, cumplen el papel de motor generador de conocimiento para el bienestar de la sociedad, por lo que tienen que aportar soluciones a la problemática del despoblamiento.

En este sentido, la situación actual de pandemia está enseñando que la acumulación excesiva es insostenible, no sólo a nivel sanitario sino también a nivel económico, social y medio ambiental. De hecho, la crisis sanitaria de la Covid-19 ha puesto de manifiesto la necesidad de disminuir la densidad de población de las ciudades para reducir la tasa de contagio. Y qué mejor forma de hacerlo que trasladando esa población a los municipios rurales despoblados. 